\title{
Narrativas dos docentes acerca dos desafios e estratégias de enfrentamento das dificuldades no exercício da profissão
}

Josivânia Sousa Costa Ribeiro ${ }^{1}$, Maria José de Pinho ${ }^{2}$

\begin{abstract}
Resumo
Este trabalho tem como objetivo narrar as vivências de docentes no exercício da profissão em uma Escola Municipal de Palmas-TO. Destarte, pretendemos relatar dados referentes à profissão, como a escolha, a satisfação e atualização profissional, os desafios e as dificuldades, além de apresentar características resilientes desenvolvidas no âmbito escolar. A metodologia usada foi História Oral Temática. Diante das narrativas das docentes participantes deste trabalho, percebe-se que a escolha da profissão se deu inicialmente por falta de outras opções, mas no decorrer do curso se identificaram e demonstraram que gostam da profissão e se dedicam a ela, apesar de destacarem fatores que podem ser melhorados no contexto escolar, tais como: acreditam que a profissão deveria ser mais valorizada; deve haver envolvimento dos pais na vida escolar dos filhos; a carga horária é excessiva; há indisciplina e desinteresse por parte dos alunos. Nesse caminho, entre os desafios e os enfrentamentos das dificuldades com planejamento e apoio de toda a equipe escolar, a resiliência é primordial para superação das adversidades e a capacidade de se manterem íntegros, proativos fortalecendo o desempenho das atividades profissionais com competência, conhecimento, dedicação, entusiasmo e amor.
\end{abstract}

\section{Palavras-chave}

Desafios. Enfrentamentos das dificuldades. História oral. Profissão docente.

\footnotetext{
${ }^{1}$ Mestra em Educação pela Universidade Federal do Tocantins, Brasil; pedagoga na Pró-reitoria de Extensão, Cultura e Assuntos Comunitários da Universidade Federal do Tocantins, Brasil. E-mail: josivaniascr@uft.edu.br.

2 Doutora em Educação e Currículo pela Pontifícia Universidade Católica de São Paulo, São Paulo, Brasil; estágio pós-doutoral na Universidade do Algarve, Portugal; professora associada IV na Universidade Federal do Tocantins, Campus Palmas; membro da Rede Internacional de Escolas Criativas: construindo a escola do século XXI (RIEC Coord. UB/Espanha). E-mail: mjpgon@uft.edu.br.
} 


\title{
Teaching narratives about the challenges and strategies for coping with difficulties in the exercise of the profession
}

Josivânia Sousa Costa Ribeiro ${ }^{3}$, Maria José de Pinho ${ }^{4}$

\begin{abstract}
This article aims to narrate the experiences of teachers in the exercise of their profession in a Palmas Municipal School, State of Tocantins, Brazil. Thus, we intend to report data related to your profession, such as choice, satisfaction and professional updating, challenges and difficulties, besides presenting resilient characteristics developed in the school environment. The methodology used was Thematic Oral History. Given the narratives of the teachers who participated in this work, it is clear that the professional choice was initially due to the lack of other options, but during the course they identified and demonstrated that they like and dedicate themselves to the profession, despite highlighting factors. This can be improved in the school context, such as: believes that the profession should be more valued; there must be parental involvement in their children's school life; the workload is excessive; there is indiscipline and disinterest on the part of the students. Thus, among the challenges and confrontations of the entire school staff, resilience is critical to overcome adversity and the ability to stand, proactively strengthening the performance of professional activities with competence, knowledge, dedication, enthusiasm and love.
\end{abstract}

\section{Keywords}

Challenges. Facing the difficulties. Oral history. Teaching profession.

\footnotetext{
${ }^{3}$ Master in Education, Federal University of Tocantins, State of Tocantins, Brazil; pedagogue at the Dean of Extension, Culture and Community Affairs at the same institution. E-mail: josivaniascr@uft.edu.br.

${ }^{4} \mathrm{PhD}$ in Education and Curriculum, Pontifical Catholic University of São Paulo, State of São Paulo, Brazil, post-doctoral internship at the University of Algarve, Portugal; associate professor IV, Federal University of Tocantins, Campus Palmas, state of Tocantins, Brasil; member of the International Network of Creative Schools: building the 21st century school (RIEC Coord. UB/Spain). E-mail: mjpgon@uft.edu.br.
} 


\section{Introdução}

Este artigo apresenta a percepção dos docentes em relação ao exercício da profissão. Sabe-se que vários fatores ocorrem no contexto escolar e podem refletir no trabalho dos professores e, assim, a maneira como os docentes lidam com os desafios e os enfrentamentos das dificuldades no exercício da profissão são determinantes para o bom desempenho educacional.

Serão contextualizados dados relevantes em relação à atuação docente, como escolha da profissão, grau de satisfação diante das exigências do trabalho docente, se em algum momento já pensou em mudar de profissão, quais as maiores dificuldades enfrentadas em sala de aula e quais estratégias adotadas para o enfrentamento das dificuldades, entre outras questões.

Sabe-se da importância dos docentes no processo de ensino e aprendizagem, pois são mediadores do conhecimento, e o seu trabalho, desempenhado com dedicação e afetividade, fará com que os educandos aprendam melhor e sintam-se motivados a buscarem sempre mais conhecimentos. Portanto, entende-se que a atuação dos docentes de forma comprometida, responsável e resiliente é primordial para uma educação significativa e emancipadora.

Para alcançar os objetivos propostos nesse trabalho, buscou-se a metodologia da história oral temática, que possibilitou a escuta da trajetória profissional das docentes ${ }^{5}$ participantes desta pesquisa. De acordo com Thompson (1992 p. 17), a história oral pode dar grande contribuição e relevância para o resgate da memória nacional, "é preciso preservar a memória física e espacial, como também descobrir e valorizar a memória do homem. A memória de um pode ser a memória de muitos, possibilitando a evidência dos fatos coletivos".

A abordagem realizada foi qualitativa, que, para Prodanov e Freitas (2013), tem o ambiente como fonte direta dos dados, enquanto o procedimento utilizado nesta pesquisa foi a pesquisa de campo com o propósito de buscar informações e/ou conhecimento a respeito do problema apresentado. Prodanov e Freitas (2013, p. 59) afirmam que a pesquisa de campo consiste na elaboração de fatos e fenômenos, tal como ocorre espontaneamente na coleta de dados".

Os instrumentos utilizados para a realização das entrevistas semiestruturadas seguiram o método da história oral que teve roteiro elaborado pela pesquisadora, no qual se objetivou

\footnotetext{
${ }^{5}$ As falas das docentes foram transcritas na íntegra, mantendo o sentido articulado pelas narradoras.
} 
colher informações dos docentes a respeito do objeto de estudo. Para Verena Alberti (2005, p. 31), "a escolha dos entrevistados não deve ser predominantemente orientada por critérios quantitativos, por uma preocupação com amostragens, e sim a partir da posição do entrevistado no grupo, do significado de sua experiência".

A seguir, apresentam-se os dados coletados relevantes em relação à profissão docente - escolha profissional, processo de formação continuada dos docentes - os principais desafios e as estratégias de enfrentamento das possíveis dificuldades no contexto escolar e a importância do fortalecimento da resiliência para atuação profissional.

\section{A profissão docente: escolha profissional}

Já se tornou comum afirmar que houve aumento das pesquisas relacionadas aos professores e da atenção dispensada a eles nas últimas décadas. Nesse contexto, o tema profissionalização tem se destacado em vários estudos nacionais (PIMENTA, 2013; CUNHA, 2001) em uma tentativa de ressignificação do estatuto profissional do professor.

Anastasiou (2013) ressalta que para o avanço na profissionalização docente é imprescindível sentir-se bem no grupo, aprendendo ou aperfeiçoando o ato de conciliar a existência natural do pensamento contraditório, gerando oportunidades sistemáticas de crescimento pessoal e grupal para o trabalho coletivo, além de florescer os processos cerebrais de mediação e desenvolvimento para lidar com o outro.

Na visão de Tardif (2014, p. 234) “o trabalho dos professores deve ser considerado como um espaço prático específico de produção, de transformação e de mobilização de saberes e, portanto, de teorias, de conhecimentos e de saber-fazer específicos ao ofício de professor". Corrobora-se da ideia do autor no sentido em que é valorizado o trabalho desenvolvido pelos professores como primordial para a transformação dos educandos e consequentemente da sociedade em geral.

O importante, no entanto, é que o professor tem papel decisivo no processo de educação do país. Sobre isso, Nóvoa (1992, p. 28) explica que

Os professores têm de se assumir como produtores de sua profissão. Mas, sabemos que hoje não basta mudar o profissional, é preciso mudar também os contextos em que ele intervém (HOLLY; MCLOUGHIN, 1989; LYONS, 1990). Isto é, da mesma maneira que a formação não pode dissociar da profissão de saber, também não se pode alhear de uma intervenção no terreno profissional. As escolas não podem mudar sem o empenhamento dos professores. E estes não mudam sem uma transformação das instituições em 
que trabalham. O desenvolvimento profissional dos professores tem de estar articulado com as escolas e os seus projectos.

Os docentes têm papel importantíssimo no processo educacional, sendo a sua atuação determinante para o sucesso ou fracasso na aprendizagem dos educandos. Nesse sentido, a escolha consciente da profissão poderá influenciar positivamente no trabalho realizado nas instituições de ensino.

As docentes entrevistadas, Silva, Neres e Moreno (2016), relatam que na época de sua formação havia poucas possibilidades de cursos ofertados, então, cursavam o que estava disponível em suas cidades. Destaca-se a transcrição de uma entrevistada a seguir:

Desde quando estava no Ensino Médio. Que na minha época que eu fiz o Ensino Médio, era o Magistério. Na minha cidade só tinha magistério e curso de contabilidade, aí eu já optei pelo magistério, "né", questão de horário e tudo. E lá já me apaixonei durante o curso. (NERES, 2016).

A vida é permeada por escolhas que podem ser simples ou complexas, planejadas ou não, que satisfazem ou que fazem repensar as decisões tomadas anteriormente. Atualmente, observa-se que a escolha da profissão muitas vezes tem sido decidida pela remuneração e pelas ofertas do mercado de trabalho, não sendo levadas em consideração as aptidões e habilidades. Para Soares (2002), a profissão é parte intrínseca da vida das pessoas, sendo imprescindível para obtenção de recursos para sua subsistência e de sua família.

Com intuito de conhecer melhor sobre as escolhas, as entrevistadas foram indagadas sobre o que as fizeram querer ser professoras. "Ah! Sei lá! Me espelhei muito nos professores da época no magistério. Eram professores bons, a didática que eles utilizavam, as dinâmicas, toda aquela estrutura de sala de aula, e tudo. Me apaixonei” (NERES, 2016).

Ademais, a ação do professor deve ser comprometida, pois será exemplo para os alunos que no futuro poderão ser professores por terem tido boas referências enquanto educandos. Cunha (2001, p. 88-89) afirma que os saberes constitutivos da profissão docente implicam:

Consciência, compreensão e conhecimento. Sobre essas bases é que se pode estabelecer a reflexibilidade e, com ela, uma perspectiva mais emancipatória da profissão. [...] Sem pieguices, o que nos estimula é o semblante de nossos alunos, ávidos por um mundo melhor, provocando a nossa reação, desinstalando o nosso ceticismo, precisando acreditar no poder de sua geração, querendo ser parceiros de uma nova ordem social. 
Para Soares (2002), a importância da escolha profissional é responsabilidade de cada um, porém as consequências de uma escolha apresentam inúmeras implicações não apenas para o indivíduo, como para toda a sociedade. A pessoa que exerce sua profissão como realização pessoal tem mais motivação para prestar o serviço com melhor qualidade à sociedade.

Moreno (2016) diz:

Os caminhos foram me levando até aqui, mas eu creio que hoje, pelas situações que já vivi, pela experiência que eu tenho, embora seja pouca, eu creio que hoje eu tenha mais consciência da profissão que eu exerço. Então assim, tem suas dificuldades, tem, mas em meio a essa dificuldade, eu consigo colocar pontos positivos e consigo me firmar na minha profissão e também, tenho aquela consciência de que, é uma profissão difícil, é, mas... mas é essa é onde eu me sinto útil, é nessa onde eu coloco projetos, onde eu quero minha satisfação.

Em relação à satisfação com a remuneração em função das exigências do trabalho desenvolvido na docência, as entrevistadas relataram: "Não considero, 'né' porque a gente observa que hoje, 'né'. Assim, as pessoas 'né' elas não ganham o suficiente para aquilo que ela realmente merece 'né', no seu trabalho atualmente" (SILVA, 2016); "Eu não acho satisfatória 'pela' complexidade que é atendimento das crianças. É um trabalho bem estressante, cansativo. Tanta carga horária quanto a remuneração" (NERES, 2016). Nesse sentido, Moreno (2016) declara:

Diante de tudo que a gente precisa trabalhar em sala de aula, pelas dificuldades que a gente vive na escola, eu acredito que essa remuneração deveria ser bem melhor e, também, o nosso acesso a outros cursos como especialização, como um mestrado, as outras oportunidades [...] ser privilegiado com bolsas de estudos para crescer profissionalmente, crescer financeiramente, também. Eu creio, que nós temos, muitas coisas a melhorar em termos de educação, ainda mais quando se trata de educação em tempo integral.

Evangelista (2013, p. 34) pontua que "à desqualificação do professor segue-se a sugestão de intervenção, seja em sua formação, no seu salário, em sua avaliação, em seu trabalho". Nota-se que a valorização do professor perpassa também pela remuneração, seu trabalho pode ser mais rentável, tendo em vista o desenvolvimento das suas atividades, bem como o valor que ele representa à sociedade.

Os docentes, em seus depoimentos, demonstraram que gostam da profissão apesar de enfrentarem algumas dificuldades no exercício docente. Mas, ao serem questionados se já 
pensaram em mudar de profissão, as entrevistadas afirmaram que em algum momento pensaram nessa possibilidade, conforme relatos a seguir: Dessa maneira Silva (2016) "Apesar de eu gostar muito da docência hoje [...]. Mas assim, "teve" vários fatores que "contribui”". Tipo, remuneração [...]. Os alunos também não têm interesse" e conclui sua fala "então, isso gera um grande estresse na nossa vida”. Nesse sentido, a entrevistada revela que apesar de gostar da sua profissão já pensou em trocar por outra atividade, devido às dificuldades acima relatadas.

Para Neres (2016) no momento de estresse, "de cansaço (risos)... de cansaço mesmo, final de ano, pensar assim '- Oh, meu Deus, ano que vem eu poderia estar em outro lugar, que fosse mais valorizada, que tivesse encerrando o ano com mais tranquilidade"'. Observa-se na fala da docente que o estresse gerado pelas demandas, principalmente das atividades realizadas ao final do ano refletem nela a possibilidade de mudança de profissão.

E, Moreno (2016) desabafa:

Quando você se depara com "muito" alunos difíceis e, justamente, aqueles que a família não dá atenção e coloca na escola para que o professor corrija, porque hoje em dia a família ela quer muito se isentar da sua responsabilidade e quando a família é convocada para escola, para a gente sentar e conversar sobre o andamento do aluno, a família pode até ouvir, pode até concordar com o que a gente coloca mas não toma uma... uma atitude, não toma posição. "- É o meu filho, eu tenho que ajudar. Eu tenho que colocar limite. Eu tenho que coloca disciplina”. Então, é nesse momento, assim, que, às vezes, que eu entro nessa questão de procurar uma nova profissão. (MORENO, 2016).

Segundo Kaloustian (2004), a família é indispensável para a garantia da sobrevivência e da proteção integral dos filhos independentemente da estrutura familiar ou da forma como ela se estrutura. É a família que propicia a construção dos laços afetivos e a satisfação das necessidades no desenvolvimento dos filhos, desempenhando um papel decisivo na socialização e educação.

Depreende-se do exposto que embora os docentes tenham afirmados que gostam da profissão, em momentos de adversidades e turbulências no ambiente educacional já pensaram em desistir desse trabalho e buscar novas profissões. No bojo das discussões, há que se problematizar os fatores elencados pelos docentes como determinantes para uma possível ruptura.

Nessa perspectiva, a educação necessita ser prioridade para os governantes e para a sociedade, valorizando os profissionais da educação com uma remuneração digna e melhores condições de trabalho. Enquanto não houver essa valorização, torna-se difícil a participação Rev. Ed. Popular, Uberlândia, v. 20, n. 1, p. 214-232, jan.-abr. 2021. 
dos docentes de forma ativa no processo de formação. Segundo Oliveira (2013), o desafio é fazer com que o investimento docente em seu crescimento profissional não resulte em mera sobrecarga de trabalho, em mais atividades a serem realizadas de forma burocrática, para atender às exigências e às determinações dos gestores das escolas ou das secretarias, que o investimento docente possa gerar melhores condições de trabalho e satisfação profissional.

Almeja-se que esse esforço represente, sim, um elemento de elevação intelectual e ética dos professores. Nesse sentido, Nóvoa (1999, p. 25) argumenta que "para além da tradicional autonomia da sala de aula, os docentes têm de adquirir margens mais alargadas de autonomia na gestão da sua própria profissão e uma ligação mais forte dos atores educativos locais (autarquias, comunidades etc.)"'.

Precipuamente, há que se levar em consideração a vontade pessoal dos docentes em buscar o seu crescimento profissional e intelectual por meio da formação. Os gestores devem ofertar espaços de aprendizagem, contudo, elas não podem ser impositivas, uma vez que podem causar descontentamento e desinteresse dos docentes, pelo contrário, deve ser espaço de crescimento e satisfação.

Penin (2008, p. 649), estabelecendo relações entre escolha profissional e vida pessoal, afirma que:

Ao escolher ou ser levada a entrar numa profissão, uma pessoa também define um modo de vida. Ela começa a pertencer a um grupo de pessoas que, conforme seu grau de identidade, pode lhe trazer benefícios ao atender uma das necessidades humanas básicas, a de pertencimento. A vivência de uma profissão [...] geralmente interfere de maneira vigorosa no desenvolvimento da própria identidade.

Ao ingressar em uma profissão as pessoas passam a fazer parte daquele universo e buscam o pertencimento por meio de seu envolvimento e lutas para que sejam inseridas e valorizadas. Quando isso não acontece, por inúmeros motivos, os docentes chegam, às vezes, a pensar em mudar de profissão. Destarte, para mudar esse cenário há que se investir na educação valorizando o trabalho desenvolvido pelos docentes que têm muito a contribuir com o aprendizado dos estudantes e consequentemente com a sociedade contemporânea.

\section{Processo de formação continuada dos docentes}

Com base no Relatório da Comissão Internacional da Educação para o Século 21, o qual estabelece os Quatro Pilares da Educação: aprender a conhecer, aprender a fazer, 
aprender a conviver e aprender a ser (DELORS et al., 1998, p. 152) alerta para a necessidade de que:

A educação deve tentar vencer esses novos desafios: contribuir para o desenvolvimento, ajudar a compreender e, de algum modo, a dominar o fenômeno da globalização. Favorecer a coesão social. Os professores têm um papel determinante na formação de atitudes - positivas ou negativas perante o estudo. Devem despertar a curiosidade, desenvolver a autonomia, estimular o rigor intelectual e criar condições necessárias para o sucesso da educação formal e da educação permanente.

Diante das mudanças que caracterizam a contemporaneidade, faz-se necessária a formação continuada dos docentes com o intuito de que estejam preparados para a complexidade vivenciada no cotidiano.

Deve haver uma formação que possibilite a construção do conhecimento a partir de conexões com os valores para uma cidadania planetária. Essa reforma do pensamento e do ensino é descrita por Morin (2007, p. 35) como um "empreendimento histórico que deverá ser arquitetado pelo universo docente, o que nos leva a inquirir sobre a necessidade de se pensar na formação dos formadores e na autoeducação dos educadores".

Vejamos o que as entrevistadas afirmam ao serem questionados sobre o que fazem para se manterem atualizados: Silva (2016) relata que "a gente faz muito curso pela internet, 'né'. Para poder ficar vendo [...] ficar atualizado, assim, dos cursos, também. O município, também, às vezes, gera algum curso e a gente faz. É dessa forma".

Para Morin (2001), a necessidade de formar professores é uma das suas motivações e contribuições, bem como a necessidade de formação permanente ao longo do exercício da docência. Nessa perspectiva, compreende-se a formação continuada como um espaço de construção e socialização do conhecimento que precisa ampliar e consolidar o envolvimento com as demandas contemporâneas.

Neres (2016) relata: "estudando, lendo livros, participando de cursos, é [...] tanto da rede quanto de [...] especialização. Estudando". Para a entrevistada, a escola onde trabalha proporciona formação para os docentes, pois "há encontros pedagógicos, 'né', mas formação tem [...] eu já participei do Pacto, esses oferecidos pelo MEC, 'né'. O Pacto e o PróLetramento, e alguns outros oferecidos pela rede. Mas, eu também já fiz especialização”.

De acordo com Nóvoa (1992, p. 25), a formação em uma perspectiva crítico-reflexiva deve "fornecer aos professores os meios de um pensamento autônomo que facilite as dinâmicas de autoformação participativa". E esse processo "implica num investimento pessoal, num trabalho livre e criativo sobre os percursos e os projetos próprios, com vista à Rev. Ed. Popular, Uberlândia, v. 20, n. 1, p. 214-232, jan.-abr. 2021. 
construção de uma identidade que é também uma identidade profissional" (NÓVOA, 1992, p. 25)

Moreno (2016), por sua vez, informa; “eu gosto muito de ler. Às vezes, quando eu tenho uma dificuldade num certo conteúdo ou num certo assunto que vi na faculdade, então eu tenho que recorrer à internet para pesquisar ou, então, trocar ideias com colegas. É isso".

A partir dos relatos apresentados pelos sujeitos dessa pesquisa, observa-se que há formação continuada ofertada tanto pela escola como pela rede municipal de ensino. Embora, os participantes tenham demonstrado que buscam a formação também por conta própria. Coaduna-se que o processo de formação continuada deve ser proporcionado e os docentes devem se sentir abertos, com desejo de aprender. Os resultados virão em forma de aulas mais dinâmicas, contextualizadas para que os estudantes consigam aprender cada vez mais.

É notável para os pesquisadores e estudiosos que a formação continuada contribui para o desempenho dos docentes e a aprendizagem significativa dos estudantes. Todavia, para que a educação seja efetiva deve-se levar em consideração também o ambiente de trabalho e como os profissionais o avaliam. Sobre isso, Silva (2016) afirma: "a relação do meu ambiente de trabalho, aqui, é excelente. Eu gosto muito da equipe, de todo mundo, assim, do gestor, eles são, realmente, assim, sabe, de grande importância 'né' para o bom andamento”. Neres (2016) acrescenta: “tranquilo. Eu gosto daqui, dos colegas e todos". E Moreno (2016): “eu avalio de uma forma bem positiva. Gosto muito do ambiente, das pessoas".

Diante das afirmativas das docentes, nota-se que avaliam como satisfatório e saudável o ambiente de trabalho. Moraes (2008), citado por Suanno e Silva (2013), analisa que os ambientes de aprendizagem precisam ser criativos, dialógicos, inovadores, prazerosos e emocionalmente saudáveis.

\section{Desafios e estratégias de enfrentamentos das dificuldades encontradas no contexto escolar}

Os desafios e as dificuldades fazem parte da vida dos seres humanos e estão presentes em todas as áreas, inclusive na educação. O diferencial é conhecer e reconhecer que elas existem e a partir de então, buscar alternativas traçando estratégias de enfrentamento com o intuito de superar os entraves apresentados.

Diante desse contexto, nota-se a fala dos entrevistados a seguir. Silva (2016) esclarece: 
O maior desafio hoje 'né', assim, que observo 'são' dos alunos 'né'. O sistema, também, de ensino hoje, [...] que parece que a gente tem que aprovar os meninos, entendeu? Mesmo eles não sabendo de muito conteúdo e, também, os pais, não tem interesse em 'tá' ensinando os filhos. Eu não falo todos 'né', mas a minoria que realmente se interessa, a maioria não 'tá' nem aí e, também, isso também gera um grande estresse, também. Os pais também não contribuem muito na educação dos filhos.

Ao falar de competências do professor profissional, Altet (2001) argumenta que os professores são profissionais do ensino e da aprendizagem, formados para conquistar as competências necessárias ao ato de ensinar (o saber ensinar) e não apenas para dominar conteúdo do ensino. Altet (2001, p. 26) define o ensino como um processo interpessoal e intencional,

que utiliza essencialmente a comunicação verbal e o discurso dialógico finalizado como meios para provocar, favorecer e levar ao êxito a aprendizagem em uma dada situação; é uma prática relacional finalizada. Ensinar é fazer aprender e, sem sua finalidade de aprendizagem, o ensino não existe. Porém, este "fazer aprender" se dá pela comunicação e pela aplicação; o professor é um profissional da aprendizagem, da gestão de condições de aprendizagem e da regulação interativa em sala de aula.

No processo educacional, o professor é o mediador da aprendizagem, cabe a ele acompanhar e avaliar os desempenhos dos alunos nas atividades realizadas no cotidiano escolar, analisando e valorando cada atividade proposta. Isso não exime o apoio pedagógico por parte da equipe escolar, auxiliando e dando suporte ao professor com o objetivo de que os conteúdos planejados sejam alcançados com sucesso. Silva (2016) afirma:

Sinto vulnerável é quando eu dou minha aula, entendeu? Eu fui ali, planejei minha aula, dei uma excelente aula "aí" no final, "aí" você faz um questionamento pro aluno, pergunta se entendeu alguma coisa, o aluno responde algo que não tem nada a ver. Como enfrentamento, tento sempre manter a calma. Porque eu já vi muitos colegas meus "né", assim [...] de profissão de licença médica "né", porque estão com esse desafio.

Segundo Tardif e Lessard (2005), a profissão enfrenta dilemas e tensões em diversos aspectos e em diferentes níveis. Assim sendo, é na ação que os docentes interagem com as adversidades, agregam conhecimentos e estruturam o fazer pedagógico.

Neres desabafa:

Carga horária, quantidade de alunos em sala de aula e relacionamento paisescola. Pais mais presentes, participar mais da vida escolar do filho, não é só 
deixar o menino na porta da escola $7 \mathrm{~h} 30 / 18 \mathrm{~h}$ e ficar por isso mesmo. Eu acho que o pai tem que se envolver mais no ambiente escolar.

$\mathrm{Na}$ indisciplina, eu me sinto, assim sem certas respostas, certas atitudes das crianças. Eu fico sem reação. Penso assim "Meu Deus, o que levou essa criança a fazer isso?" (risos) Aí vou pensar no contexto familiar, toda aquela situação mas, geralmente, naquele momento, eu fico vulnerável. Mas, como estratégia de enfrentamento gosto muito de conversar, de esclarecer as situações, "né". Então assim, depois do momento lá da [...] que aconteceu algo e resolveu, eu me sinto tranquila. Agora se eu não consigo resolver eu fico tendo até pesadelo à noite, mas prefiro resolver a situação.

Torre $(2009 ; 2011)$ diz que as crises e os conflitos podem se apresentar como muros que impedem de avançar, mas também podem se tornar uma possibilidade de bifurcação. Nessa perspectiva, acontecimentos que desorganizam e rompem assumem um lugar importante na trajetória dos adultos e por que não dizer dos professores, os obriga muitas vezes a renascer.

Moreno (2016) complementa:

Maiores dificuldades, eu creio, que a família. A assistência da família e quando eu [...] a gente fala "assistência", é no seguinte, se o pai e a mãe não tem um certo nível intelectual de aprendizagem, mas tem a questão da moral, então a gente, precisa disso. De que o aluno, a criança ela seja educada moralmente e quando o pai tem [...] tem esses dos lados, a questão intelectual e moral, melhor ainda.

Sella (2006) menciona, ainda, que os professores têm sido, cada vez mais, solicitados a preencher lacunas deixadas pelas famílias na transmissão de valores éticos e morais para seus filhos, bem como de costumes e hábitos socialmente acordados. Isso parece decorrer das transformações observadas nos últimos tempos no âmbito social, notadamente no caso de famílias que dividem a formação moral dos filhos com outras instituições sociais, caso em que o professor,

diante das mais variadas funções que a escola assume, tem de responder a exigências que estão atém de sua formação. Muitas vezes, esses profissionais são obrigados a desempenhar funções de agentes públicos, assistentes sociais, enfermeiros, psicólogos, entre outras (OLIVEIRA apud SELLA, 2006, p. 41).

Moreno (2016) diz: 
Quando o aluno desrespeita, tem situações de desacato, de você chamar a atenção do aluno e ele não dar a mínima para você e [...] e esses comportamentos na escola, provavelmente, é um reflexo daquilo que é em casa, às vezes, o pai e a mãe não tem dado atenção. Nas situações em que vivi isso, eu [...] procurei ter calma e recorri à orientação da escola.

Discorrendo sobre os motivos que causam sofrimento ao professor no exercício de suas atividades, Pimenta (2013, p. 105) explica que:

A relação escola-comunidade e a escola-alunos é ponto nevrálgico para as mudanças que se pretende. [...] a questão da indisciplina. Enquanto não tivermos os nossos alunos como sujeitos processo, enquanto não estabelecermos um contrato de trabalho no interior da escola, no qual os vários atores se veem representados e, portanto, os interesses equalizados em direção a uma meta de qualidade social da escola, dificilmente vamos conseguir resolver o problema da indisciplina.

A escola precisa sensibilizar e trazer a família para vivenciar o cotidiano escolar, para que ela se sinta inserida no processo educacional, pois a educação diz respeito a todos, pais, alunos, docentes, equipe diretiva, governo, enfim, todos da sociedade podem e devem contribuir com a educação, visando a uma convivência no ambiente educacional harmoniosa e respeitosa.

\section{A importância de fortalecer a resiliência no contexto escolar}

A sociedade passa por transformações constantes que exigem que os profissionais estejam preparados e busquem a formação para integrar e interagir na sociedade em que as mudanças são efêmeras. No contexto escolar não é diferente, pois o professor enfrenta, no seu cotidiano, desafios como: escassez de materiais pedagógicos, salas de aulas lotadas, alunos indisciplinados, cobrança dos pais, acúmulo de tarefas, pressão da gestão e equipe pedagógica da escola, além da necessidade de manterem-se atualizados na formação continuada para acompanhar as mudanças e desafios da sociedade contemporânea.

Nesse sentido, é importante ressaltar que a maneira pela qual os professores respondem e lidam com esses desafios é fundamental para o sucesso escolar, além de contribuir para o seu bem-estar, sua saúde e da escola. A resiliência é o elemento chave para evitar o esgotamento físico e mental, a depressão e a fadiga.

Para Cyrulnik (2004), a resiliência é a capacidade do ser humano enfrentar, vencer, aprender, crescer e mudar, quando os fatores estressores, as adversidades, interrupções e 
perdas ocorrem em nossa vida. Conforme Suanno (2013, p. 34-35), os sujeitos que têm uma postura de enfrentamento às adversidades possuem:

uma possibilidade de se tornarem cada vez mais criativas, pois exercitam suas capacidades criadoras quando em momento difíceis e também fora deles. São pessoas argutas, com flexibilidade de pensamento, ou seja, capacidade de reorganizações de suas estruturas cognitivas no planejamento de estratégias de solução, superação da dificuldade. Não se receia da tentativa, nem lança ao outro a responsabilidade de resolver e enfrentar a adversidade.

A qualidade de vida do professor reflete na qualidade da sua aula, ou seja, é importante que o professor esteja bem, pois, assim, ele terá condições de ensinar e ressignificar as aprendizagens para os alunos. A maneira pela qual os professores lidam com as situações adversas e conseguem manter ou recuperar-se em uma perspectiva saudável faz toda a diferença no processo de ensino e aprendizagem.

O conceito de resiliência é ainda pouco difundido no Brasil. José Tavares (2001) questiona o conceito dentro da sociedade atual, que se apresenta altamente ameaçada, e sugere a necessidade de se entender a resiliência como uma defesa psicológica. Ao mesmo tempo, não concebe defesa como insensibilidade ou conformismo, ou ainda resignação. O conceito apresenta uma proposta inovadora, já que consiste na habilidade do indivíduo de enfrentar e sair de situações adversas.

Resiliência é o nome dado à capacidade concreta das pessoas de não só superarem situações críticas, adversas, mas também de utilizá-las nos processos de desenvolvimento pessoal. Para Suanno (2013), o diferencial entre os sujeitos está na maneira como eles encaram as situações de sofrimento e como as transformam em aprendizagens, em pensamento criativo. Nesse contexto, não é uma tarefa tão fácil aos professores, pois exige paciência, esperança, persistência, enfim, uma capacidade de se manterem íntegros, apesar das adversidades da vida.

A palavra resiliência apresenta várias definições, de acordo com a área em que o termo é empregado. Tem origem no latim resilio, que significa retornar a um estado anterior. Para Leal et al. (2010, p. 14), a resiliência

representa a capacidade concreta das pessoas de não só retornarem ao estado natural de existência, superando situações críticas, mas também de utilizá-las em seus processos de desenvolvimento pessoal, sem se deixarem afetar negativamente, capitalizando as forças negativas de forma construtiva. 
Para Poletti e Dobbs (2007), o ambiente no qual o sujeito se encontra, a presença ou ausência de pessoas sadias ao seu redor e os contextos político, social, cultural e religioso são situações que permitem que a resiliência se manifeste mesmo onde existia grande risco devido ao acúmulo de fatores de estresse e tensão.

Para Frankl (1991), a busca pelo autoconhecimento e o fortalecimento dos valores do ser humano, como base para o desenvolvimento de sua força interior, são capazes de habilitar o homem a superar as dificuldades que a vida apresenta. Essa força hoje chamada resiliência traz, em sua essência, a harmonia entre a razão e a emoção e introspecção. A última oferece um caminho de melhoria da qualidade interna do ser.

Segundo Cyrulnilk (2004 p. 207), o conceito de resiliência envolve "um processo, um conjunto de fenômenos harmonizados em que o sujeito se esgueira para dentro de um contexto afetivo, social e cultural. A resiliência é a arte de navegar nas torrentes”. O professor resiliente é aquele que consegue, em meio às adversidades, manter-se pleno, capaz de aprender com as situações adversas, enfrentar e superar os desafios e se fortalecer diante deles.

A resiliência também é definida "como a capacidade individual ou coletiva para enfrentar, sobrepor e se transformar diante das adversidades" (ZWIEREWICK, 2009, p. 131). Ela representa um processo em que são abstraídas das adversidades as condições para redimensionar a vida e essas condições se transformam em caminhos para transpor o que, a princípio, poderia parecer intransponível.

Na escola, como na vida, nos deparamos com situações adversas que nos determinam a fazer uma tomada de decisões para o enfrentamento de tais situações. Assim, um professor resiliente poderá mais facilmente manter-se firme em sua tarefa de educar, respeitando alunos, colegas, equipe diretiva, respeitando seus limites pessoais, buscando desenvolver a prática formativa pautada no respeito mútuo.

Diante disso, a escola deve desempenhar a função fundamental no desenvolvimento da resiliência, minimizando os fatores que podem influenciar os docentes a se tornarem menos ativos, desmotivados e apáticos diante dos desafios e enfrentamentos do cotidiano.

Ademais, é primordial o fortalecimento da resiliência no âmbito escolar, tendo em vista as possibilidades de superação e/ou enfrentamento das dificuldades com atitudes de encorajamento, amorosidade e apoio afetivo por parte da equipe. Assim, os docentes, sentindo-se acolhidos, tendem a desenvolver suas atividades laborais com estabilidade emocional e confiante que as adversidades são inerentes ao ser humano e à vida. Sendo elas 
transitórias podem gerar ou não sofrimento, mas também podem ser fonte de aprendizagem e amadurecimento diante dos acontecimentos.

\section{Considerações finais}

Diante das narrativas das docentes, percebe-se que a escolha da profissão se deu inicialmente por falta de outras perspectivas, porém, no decorrer do curso, elas foram se identificando com a profissão. Demonstraram que gostam e se dedicam a ela, apesar de destacarem fatores que podem ser melhorados no contexto escolar, tais como: acreditam que a profissão deveria ser mais valorizada; deve haver envolvimento dos pais na vida escolar dos filhos; a carga horária é excessiva; há indisciplina e desinteresse por parte dos alunos, entre outros.

Evidenciou-se também que, em algum momento no exercício da função, já pensaram em mudar de profissão quando vivenciaram momentos de tensões e conflitos, que foram superados posteriormente. Percebe-se que os pontos positivos superam as dificuldades, como relata Moreno (2016) "eu acho que o maior de todos é você ser útil para a sociedade e, no meu caso, como eu dou aula para crianças [...] de crianças que, às vezes, num têm certa assistência da família, não tem atenção, não tem carinho e aqui talvez na escola seja uma forma deles encontrarem isso".

Por meio das verbalizações docentes notou-se que o processo de formação continuada corroborou para o enfrentamento das dificuldades apresentadas no exercício profissional. Nesse sentido, compreende-se a formação continuada sendo relevante e necessária como espaço de construção, socialização e ressignificação do conhecimento.

Percebe-se que os docentes almejam e merecem ser reconhecidos e valorizados, tanto pelos organismos governamentais quanto pela sociedade, pelo importante trabalho que desempenham para a educação dos educandos e por meio deles contemplam toda uma geração, levando conhecimento, condições de vida digna e expectativas de dias melhores aos cidadãos. E não há outro caminho, se não pela educação.

Nesse caminho, entre os desafios e os enfrentamentos das dificuldades com planejamento e apoio de toda equipe escolar, a resiliência é primordial para superação das adversidades e a capacidade de se manterem íntegros, proativos fortalecendo o desempenho das atividades profissionais com competência, conhecimento, dedicação, entusiasmo e amor. 


\section{Referências}

ALBERTI, V. Manual da historia oral. 2. ed. Rio de Janeiro: FVG, 2005.

ALTET, M. As competências do professor profissional: entre conhecimentos, esquemas de ação e adaptação, saber analisar. In: PERRENOUD, F. et al. Formando professores profissionais: Quais estratégias? Quais competências? Porto Alegre: Artmed, 2001. p. 23-35.

ANASTASIOU, L. G. C. Didática e formação de professores para o ensino superior. In: LIBÂNEO, J. C.; SUANNO, M. V. R; LIMONTA, S. V. Qualidade na escola pública: políticas educacionais, didática e formação de professores. Goiânia: Ceped Publicações; Gráfica e Editora América: Kelps, 2013. p. 149-172.

CUNHA, M. I. Ensino como mediação da formação do professor universitário. In: MOROSIN, M. C. (org.) Professor do ensino superior: identidade, docência e formação. Brasília: Plano, 2001. p. 45-52.

CYRULNIK, B. Os patinhos feios. São Paulo: Martins Fontes, 2004.

DELORS, J. et al. Educação: um tesouro a descobrir. Tradução de José Carlos Eufrázio. Revisão de Maria de Lourdes de Almeida e Eliana Martins. São Paulo: Cortez; Brasília, DF: UNESCO, MEC, 1998.

EVANGELISTA, O. Qualidade da educação pública: Estado e organismo multilaterais. In: LIBÂNEO, J. C.; SUANNO, M. V. R; LIMONTA, S. V. Qualidade na escola pública: políticas educacionais, didática e formação de professores. Goiânia: Ceped Publicações; Gráfica e Editora América: Kelps, 2013. p. 13-45.

FRANKL, V. E. Em busca de sentido: um psicólogo no campo de concentração. 2. ed. Petropólis-RJ: Vozes, 1991.

KALOUSTIAN, S. M. (org.) Família brasileira, a base de tudo. 6. ed. São Paulo: Cortez, 2004.

LEAL, A. L.; RUHR, F.; POLICARPO JUNIOR, J. Resiliência e espiritualidade: algumas implicações para a formação humana. Conjectura: Filosofia e Educação, Caxias do Sul, v. 15, n. 1, p. 11-24, jan./abr. 2010. Disponível em: http://www.ucs.br/etc/revistas/index.php/conjectura/article/view/173. Acesso em: 15 fev. 2020 .

MORENO, V. C. Entrevista concedida a J. S. C. R. Palmas (TO), em 21 de novembro de 2016.

MORIN, E. Educação e complexidade: os sete saberes e outros ensaios. ALMEIDA, Maria da Conceição de; CARVALHO, Edgard de Assis (org.). Tradução de Edgar de Assis Carvalho. 4. ed. São Paulo: Cortez, 2007. 
MORIN, E. Os sete saberes necessários a educação do futuro. Tradução de Catarina Eleonora F. da Silva e Jeanne Sawaya. Revisão Técnica de Edgard de Assis Carvalho. 5. ed. São Paulo: Cortez, 2001.

NERES, E. de S. P. Entrevista concedida a J. S. C. R. Palmas (TO), em 21 de novembro de 2016.

NÓVOA, A. Profissão professor. 2 ed. Porto: Porto, 1999.

NÓVOA, A. Os professores e sua formação. Lisboa: Dom Quixote, 1992.

OLIVEIRA, L. M. Trabalho docente e mudanças curriculares: um estudo sobre a rede municipal de Belo Horizonte. 2013. Tese (Doutorado em Educação) - Faculdade de Educação, Universidade Federal de Minas Gerais, Belo Horizonte, 2013.

PIMENTA, S. G. Políticas públicas, diretrizes e necessidades da educação básica e formação de professores. In: LIBÂNEO, J.,C; SUANNO, M.V. R; LIMONTA, S. V. Qualidade na escola pública: políticas educacionais, didática e formação de professores. Goiânia: Ceped Publicações; Gráfica e Editora América: Kelps, 2013. p. 91-106.

PENIN, S. T. S. Profissionalidade: o embate entre o concebido e o vivido. In: ENCONTRO NACIONAL DE DIDÁTICA E PRÁTICA DE ENSINO (ENDIPE), 14., 2008, Porto Alegre: Anais [...]. Porto Alegre: UNISINOS, 2008.

POLETTI, R.; DOBBS, B. A resiliência: a arte de dar a volta por cima. Petrópolis: Vozes, 2007.

PRODANOV, C. C; FREITAS E. C. Metodologia do trabalho científico: métodos e técnicas da pesquisa e do trabalho acadêmico. 2. ed. Novo Hamburgo: Feevale, 2013.

SELLA, C. A. Retrato de um profissional em crise: os docentes em tempos de mudança. 2006. Dissertação (Mestrado em Educação) - Universidade do Oeste de Santa Catarina, Joaçaba, 2006.

SILVA, S. L. Entrevista concedida a J. S. C. R. Palmas (TO), em 21 de novembro de 2016.

SOARES, D.H.P. A escolha profissional: do jovem ao adulto. 3. ed. São Paulo: Summus Editorial, 2002.

SUANNO, M. V. R; SILVA. C. C. Resiliência, Adversidade Criadora e Educação. In: SUANNO, M. V. R; DITTRICH, M.G; MAURA, M. A. (org.). Resiliência, criatividade e inovação: potencialidades transdisciplinares na educação. Goiânia: UEG/ América, 2013. p. 43-57.

SUANNO, J. H. Adversidade, resiliência e criatividade: uma articulação oportuna? In: SUANNO, M. V. R; DITTRICH, M. G; MAURA, M. A. (org.) Resiliência, criatividade e inovação: potencialidades transdisciplinares na educação. Goiânia: UEG/América, 2013. p. $31-42$.

TARDIF, M.; LESSARD, C. O trabalho docente: elementos para uma teoria da docência como profissão de interações humanas. 2. ed. Petrópolis-RJ: Vozes, 2005. 
TARDIF, M. Saberes docentes e formação profissional. Tradução de Francisco Pereira. 17. ed. Petrópolis-RJ: Vozes, 2014.

TAVARES, J. (org.). Resiliência e educação. 2. ed. São Paulo: Cortez, 2001.

TORRE, S. La adversidad esconde um tesoro, outra manera de ver la adversidad y la vida. El Ejido (Espanha): Círculo Rojo, 2011.

TORRE, S. Adversidad creadora: teoria e prática del rescate de potencialidades latentes. Encuentros Multidisplinares, Madrid, v. 11, n. 31, p. 6-20, abr. 2009.

THOMPSON, P. A voz do passado. São Paulo: Paz e Terra, 1992.

ZWIEREWICZ, M. Trabajar com emócion y valores para fortalecer la resiliencia en la escuela. In: TORRE, S.; PUJOL, M. A. Educar con otra conciencia: uma mirada ecoformadora y creativa de la enseñanza. Barcelona: Davinci Continental, 2009.

Submetido em 14 de abril de 2020.

Aprovado em 4 de maio de 2020. 